\title{
(t)
}

\section{RELATÓRIO DE VIAGEM: SÍNTESE DA REUNIÃO DO SERVIÇO SOCIAL RADICAL DURANTE O CONGRESSO INTERNACIONAL DE ESTOCOLMO}

\author{
Travel report: synthesis of a radical Social Work Meeting \\ during the International Conference in Stockholm
}

\section{Alzira Maria Baptista Lewgoy ${ }^{1}$ Carina Berta Moljo² Janete Luzia Leite 3 Yolanda Guerra ${ }^{4}$}

O presente texto nasce da motivação das autoras de compartilhar o registro das informações e debates ocorridos durante a reunião organizada por um grupo que se intitula Serviço Social Radical, realizada no dia 10 de julho de 2012, durante a $2^{a}$ Joint World Conference in So-

\footnotetext{
Professora Adjunta do Curso de Serviço Social da Universidade Federal do Rio Grande do Sul (UFRGS). Pesquisadora e coordenadora do Grupo de Estudos e Pesquisa em Formação e Exercício Profissional (GEFESS/UFRGS). E-mail: <lewgoy@terra.com.br>.

${ }^{2}$ Professora Adjunta do Curso de Serviço Social da Universidade Federal de Juiz de Fora. Dra. em Serviço Social pela PUC/SP, pesquisadora do CNPq, pesquisadora e coordenadora do grupo de pesquisa: Serviço Social, Movimentos Sociais e Políticas Públicas, da Universidade Federal de Juiz de Fora (UFJF). E-mail: <carinamoljo@uol. com.br>.

3 Professora Associada do Curso de Serviço Social da Universidade Federal do Rio de Janeiro (UFRJ). Pesquisadora e coordenadora do Núcleo de Pesquisa e Estudos sobre Políticas Públicas, "Questão Social” e Serviço Social (NUPEQUESS/ UFRJ). E-mail: <janeteluziaufrj@gmail.com>.

4 Professora Adjunta do Curso de Serviço Social da Universidade Federal do Rio de Janeiro (UFRJ). Pesquisadora e coordenadora do Núcleo de Estudos e Pesquisas sobre o Serviço Social na Contemporaneidade (NEFSSC/UFRJ). E-mail: <yguerra1@terra.com.br>.
} 
cial Work and Social Development: Action and impact 5 , em Estocolmo (Suécia). A iniciativa foi redirecionada pela presidente da Associação Brasileira de Ensino e Pesquisa em Serviço Social (ABEPSS), que solicitou a publicização das anotações para a categoria profissional. Assim, o Relatório de Viagem do grupo cumpre seu objetivo de socialização.

O Serviço Social Radical é uma tendência do Serviço Social contemporâneo oriunda do movimento que se desenvolveu no Reino Unido (Inglaterra, Irlanda do Norte, Escócia e País de Gales), em $1970^{6}$. A partir de então, este movimento vem ganhando a adesão de assistentes sociais de várias partes do mundo.

O encontro realizado em Estocolmo foi organizado por alguns dos expoentes desta tendência, tendo à frente os assistentes sociais do Reino Unido e Canadá7, e contou com a participação de 90 assistentes sociais (30 brasileiros), representando 17 países $^{8}$. O encontro também teve como objetivo apresentar e difundir a Revista

\footnotetext{
${ }^{5}$ Cabem aqui alguns registros históricos sobre as Conferências e Associações de Serviço Social. As Conferências Internacionais são realizadas desde 1850, e se destinavam à articulação de práticas direcionadas ao enfrentamento de catástrofes naturais e calamidades públicas, cuja continuidade somente foi interrompida em períodos de guerras mundiais. A formação profissional de assistentes sociais se inicia, nos países centrais por volta de 1900. Em 1929, em Paris, surge o Comitê Internacional de Escolas de Trabalho Social, a primeira iniciativa de organização internacional de escolas de Serviço Social, hoje conhecida como Associação Internacional de Escolas de Trabalho Social (IASSW). Paris foi também o palco onde se decidiu pela necessidade de fundar uma organização de trabalhadores sociais em 1928: a Secretaria Permanente de Trabalhadores. Mas somente em 1956, a partir da existência de 12 associações profissionais nacionais, pôde ser formada a Federação Internacional de Trabalhadores Sociais (IFSW).

${ }^{6}$ Podemos identificar uma linha de continuidade entre o movimento do Serviço Social Radical e a vertente que surgiu nos Estados Unidos, Canadá e Inglaterra nos anos 70 do século passado, que se constituiu uma alternativa ao conservadorismo da profissão e se denominou Serviço Social Radical. Assim como em 1970, trata-se de estabelecer uma crítica ao Capitalismo, ao (Neo)Liberalismo, especialmente à perspectiva de individualizar os problemas e culpabilizar os sujeitos.

7 Destacamos os colegas lain Ferguson e Michael Lavalle. O primeiro é docente do curso da School of Applied Social Science, da Stirling University e coautor, juntamente com R. Woodward, do livro Radical Soci al Work in Practice (Bristol: Policy Press, 2009); o segundo é Professor Adjunto de Serviço Social da Liverpool Hope University. Ambos estão à frente do International Journal of Social Welfare.

${ }^{8}$ Esta iniciativa foi construída no Congresso anterior, realizado em Hong Kong (2010). Lá, o Brasil participou de reunião para discutir e elaborar uma moção em defesa do fim do embargo a Gaza, que foi apresentada na assembleia da AIETS. Na reunião de Estocolmo, participaram os seguintes países: Argentina, África do Sul, Brasil, Bósnia, Bolívia, Canadá, Chile, Dinamarca Croácia, Espanha Finlândia, Grécia, Nicarágua, Portugal, Reino Unido, Suécia e Uruguai.
} 
Critical and Radical Social Work como uma inédita e importante publicação representativa de uma tendência crítica do Serviço Social mundial, visando a sua internacionalização. A revista será on line e de acesso gratuito a fim de divulgar esta perspectiva.

Inicialmente, foram feitas algumas reflexões, tendo em vista que, nos momentos de crise social, os assistentes sociais tendem a questionar-se sobre o que é o Serviço Social, sobre o que faz o profissional, ou seja, sobre o significado social e histórico da profissão. Nesse sentido, relata Michael Lavalette, do Reino Unido/ Inglaterra, houve a necessidade de articular uma rede do Serviço Social Radical para entender os problemas do mundo, estabelecer laços de cooperação, não somente teóricos, mas de atividades, de ações conjuntas.

O objetivo do encontro foi socializar as experiências do Serviço Social no mundo, entendendo a totalidade histórica do Serviço Social e a sua relação com o Capitalismo. O Serviço Social Radical, a partir da crítica ao Capitalismo, busca analisar e intervir na sociedade.

Os diferentes interlocutores expuseram a conjuntura de seu país de origem e do Serviço Social neste contexto.

O Brasil ${ }^{9}$ fez a sua apresentação por meio da Presidente do Conselho Federal de Serviço Social (CFESS), Sâmya Rodrigues Ramos, que dissertou sobre o processo de Renovação Crítica do Serviço Social brasileiro, existente há mais de 40 anos; e a importância deste processo de amadurecimento para o trabalho e a formação profissional (nos níveis teórico-metodológico, prático-operativo e organizativo). Destacou a relevância da articulação entre as entidades representativas da categoria profissional e dos estudantes para o processo de consolidação do nosso projeto de renovação, e enfatizou as ações do CFESS. A professora Claudia Mônica dos Santos, presidente da ABEPSS, completou a fala de Sâmya, explicitando que a ABEPSS tem encaminhado o projeto de formação

\footnotetext{
9 O Congresso Mundial de Serviço Social contou com 2.108 participantes, dos quais 198 eram brasileiros. O Brasil participou com 290 trabalhos (176 para apresentação oral e 114 pôsteres) oriundos de todas as regiões do país. O que chama atenção é a predominância de trabalhos provenientes das regiões Sudeste, Sul e Nordeste, respectivamente, originados, majoritariamente, em universidades públicas (vários em colaboração com universidades privadas e instituições públicas, somente três em parceria com universidades do exterior).
} 
profissional em vigor, em uma direção crítica, numa relação entre formação e exercício profissional. A participação da Executiva Nacional de Estudantes de Serviço Social (ENESSO) também tem sido fundamental para a consolidação deste processo. Ressaltou, ainda, a importância da pós-graduação, que, atualmente, conta com 30 Programas em todo o país. A professora Claudia Mónica também destacou que estamos vivendo em um momento difícil nas universidades federais do Brasil, quase a totalidade delas em greve lutando por uma educação pública, gratuita e de qualidade. Nesta oportunidade, foi distribuído um exemplar, com as versões em Português, Inglês e Espanhol, do Código de Ética Profissional dos Assistentes Sociais Brasileiros (1993), reafirmando seus princípios de justiça, liberdade e democracia, e da Lei de Regulamentação da Profissão (Lei n 8662, de 1993).

Vassilios Loalcimídis, da Grécia, informa que o Serviço Social Radical vem crescendo e se fortalecendo, nos últimos anos, em seu país. Expôs como o Estado grego tem sido "duro" com os movimentos populares, pois vem reprimindo os movimentos de resistência existentes hoje, considerando a crise econômica que sofre este país na atualidade. Destacou, ainda, que os assistentes sociais estão no cerne da questão, e como esses profissionais vêm resistindo ante a repressão, assim como diante da pressão que sofrem do Estado para utilizar medidas coercitivas com a população pobre. Os assistentes sociais se negaram a realizar esta tarefa - no que foram apoiados pela sociedade -, e, agora, estão sendo perseguidos e criminalizados pelo governo. Vassilios reforçou a importância desta Rede para a defesa dos direitos humanos e, como estratégia de pressão, em todos os países, contra a criminalização do Serviço Social por parte do governo, visando ao enfrentamento com este.

A representante de Portugal iniciou o seu relato fazendo uma reflexão sobre a crise político-econômica atual no seu país. Analisou a fragmentação do Serviço Social neste país, caracterizada pela precarização profissional e pelo corte nos salários, já que, em Portugal, não há instituições de representação coletivas. Para a profissional, o Serviço Social Crítico está presente somente na academia. Ela afirma que os assistentes sociais defendem os interesses dos usuários, mas isto não quer dizer que possuam uma 
perspectiva critica, posto que os usuários não são tratados como "sujeitos". A assistente social denuncia um problema sério que Portugal vem enfrentando: os jovens que deixam o país em busca de trabalho em outros lugares da Europa, inclusive os próprios assistentes sociais, devido ao alto índice de desemprego. Salienta que os assistentes sociais não são chamados pelo Estado para debater as políticas sociais e que, pelo contrário, é o Terceiro Setor que vem ganhando força e espaço no interior da sociedade portuguesa. Conclui, afirmando que a categoria está desorganizada e solicita apoio internacional.

A assistente social da Bósnia analisou as implicações, para o país, da transição do Socialismo para o Capitalismo, registrando que, neste momento, o Serviço Social se encontra em uma situação intermediária, passando para o modelo gerencial. Atualmente, o Serviço Social na Bósnia se baseia no modelo inglês, mas este é muito administrativo e individualizado, e trabalha, basicamente, com o Serviço Social de Caso, de cunho conservador. A sociedade vive em um momento de privatização e redução de recursos. Estas medidas são fortemente combatidas pelos movimentos sociais, que buscam articulação com o Serviço Social para ações de enfrentamento. Embora haja uma adesão dos profissionais a estas ações, a categoria não consegue se organizar profissionalmente.

O representante da Finlândia estava presente, mas como havia uma sessão específica para apresentação do Serviço Social em seu país no dia seguinte, preferiu deixar sua apresentação para este momento ${ }^{10}$.

A participante da Croácia apresentou uma situação similar à da Bósnia, uma vez que este país também experimenta uma trajetória rumo ao Capitalismo. Há, ainda, uma ideologia socialista permeando a sociedade, mas esta não é hegemônica e nem colocada em prática. O governo, embora socialdemocrata, vem implementando a política neoliberal. Recentemente, a Croácia incorporou-se à União Europeia, o que implicou adaptar-se e assumir os padrões europeus de industrialização. Observa-se, nesta adaptação, uma desregulamentação da legislação trabalhista, o

${ }_{10} \mathrm{O}$ registro da exposição deste assistente social não foi possível porque não havia intérprete quando da sua apresentação. 
que está sendo dificultoso para este país. São essas as questões que o Serviço Social tem que enfrentar.

Linda Smith, da África do Sul, abordou a diferença do trabalho desenvolvido lá e aquele de outros países. Centrou o seu relato nas diferenças étnicas e políticas que existem na África, analisando que os assistentes sociais não estão preparados para trabalhar com os conflitos derivados destas diferenças étnicas, políticas e culturais. Enfatizou que o apartheid de hoje é muito mais econômico que racial. Entretanto, o grande problema enfrentado pela categoria é o desemprego dos recém-formados, malgrado o grande empenho do governo na formação profissional durante o período universitário por meio do recebimento de bolsas acadêmicas. Para tentar uma unidade de enfrentamento, formaram uma trade union ${ }^{11}$, atualmente com 1.150 profissionais a ela vinculados.

A representante da Espanha relata que a situação de seu país é muito semelhante a dos países do Mediterrâneo, ou seja, a crise econômica não permite que se vislumbre nenhuma saída, não se vê futuro. Existe uma grande pressão dos mercados externos, que se materializa em cortes nos gastos públicos (cita como exemplos a saúde, os serviços sociais e a proteção social - incluindo-se aí as pensões e aposentadorias), com aumento do desemprego. $\mathrm{O}$ alto custo dos alimentos básicos, leite, luz e água só piora a situação social da população. Os serviços são cada vez mais caros. Não há dinheiro para universidades e para as organizações sociais. A assistente social analisou como a Espanha está voltando a ver a família como a principal responsável pela atenção às necessidades sociais, colocando-a num papel central. Na Espanha, disse ela, a família é o verdadeiro Estado organizado. Explica que a Espanha já tinha passado por um processo de desinstitucionalização e hoje está voltando às políticas sociais que buscam a institucionalização, somada à responsabilização da família. Também ressaltou o crescimento do voluntariado, com o retorno das instituições não-profissionais do Serviço Social. Analisa que é necessário que a população se mobilize e se organize politicamente para reivindicar a revogação destas

\footnotetext{
"As trade unions são originárias da Inglaterra do século XIX, e se constituíam em associações de trabalhadores para defender seus interesses. São consideradas como os primeiros sindicatos.
} 
medidas. Existe um baixo orçamento para as universidades, para a pesquisa e para a extensão. Os assistentes sociais espanhóis possuem o Conselho Geral de Assistentes Sociais, que está se articulando para denunciar a situação crítica pela qual atravessa o país. Também consideram importante esta rede internacional. Ao concluir, enfatiza que a Espanha possui problemas de causas internas, e o governo atual não se dá conta da magnitude da crise.

A Suécia apresentou duas visões da situação de seu país. A primeira indicava que a crise sueca não é igual a do resto da Europa, já que o problema que apresenta não é o econômico, como outros países, e sim referente à burocratização do Serviço Social, que possui uma prática conservadora - é um Serviço Social acrítico e burocrático. Isto deriva do fato de a socialdemocracia, na Suécia, ser opressora e sexista, uma vez que imputa os problemas nas políticas sociais à ideologia, e não à economia. A segunda versão, a partir da discordância de outro assistente social, é de que a Suécia está sofrendo os impactos da crise econômica que assola a Europa, que se traduz na redução de gastos no Estado de Bem-Estar Social sueco. Relata: "[...] sofremos, sim, cortes nos gastos sociais, redução de custos e desemprego. Contudo, não é tão acirrado quanto nos outros países, mas há rebatimentos da política econômica internacional”. Há uma individualização crescente da sociedade, que se manifesta nas políticas sociais, que trabalham numa perspectiva individualista, e também no Serviço Social, que deixou de trabalhar para a coletividade e agora está trabalhando individualmente.

O representante do Uruguai fez uma reconstrução histórica do que aconteceu em seu país na época da Ditadura Militar, dos desaparecidos políticos, do cerco que era colocado para o Serviço Social. Afirmou que o Serviço Social uruguaio sempre possuiu uma perspectiva crítica. Neste momento, o Uruguai está apostando na ampliação e na consolidação das políticas públicas, mas ainda tem muito para fazer. Enfatiza o compromisso com o Serviço Social Crítico e com os assistentes sociais desaparecidos durante a Ditadura.

Finalizando o encontro, Michael Lavalette enfatizou a importância desta articulação internacional, ressaltando que a criação de 
uma rede viabilizaria trabalhar a comunicação dos interesses coletivos e da interlocução, um valor central que deve congregar os assistentes sociais radicais de todo o mundo.

Avaliamos que este encontro foi de suma importância, uma vez que representou mais um passo para dar visibilidade à presença do pensamento crítico no circuito profissional de outros países, além de aglutinar esta tendência aos assistentes sociais que participam do Serviço Social Radical.

Destacamos, como um aspecto marcante na reunião, a necessidade de consolidarmos princípios e estratégias para construção de vínculos com as tendências críticas, combatentes e radicais existentes nos outros países. Também, a defesa dos direitos humanos e da democracia; pela relação direta e de respeito pelos usuários, pela garantia da qualidade dos serviços e políticas que executamos, que são princípios pelos quais podemos estabelecer uma agenda de debates, enfatizando os seguintes temas:

1) Análise sobre a crise econômica mundial (e suas particularidades em casa país); a denúncia de que os trabalhadores estão pagando a conta, e a construção de estratégias coletivas que tirem dos ombros da classe trabalhadora o pagamento da crise; a defesa dos direitos conquistados e a garantia da sua universalização; a articulação e fortalecimento das lutas sociais, e o engajamento nos movimentos críticos e progressistas;

2) Estratégias de realização de eventos nacionais e internacionais que promovam o conhecimento, difundam a produção própria, e fomentem o debate crítico por meio da produção coletiva de conhecimento, de intercâmbio profissional, discente, docente e de produção bibliográfica.

Concluindo, registramos a importância de reafirmar a articulação construída no Brasil, e o reconhecimento do seu papel protagônico na organização de uma articulação internacional. Para tanto, é fundamental a nossa participação nas entidades internacionais: Associação Internacional de Escolas de Serviço Social (IASSW), Conselho Internacional de Bem-Estar Social (ICSW) e Federação Internacional de Trabalho Social (FITS). 
Há, ainda, um grande trabalho a fazer. Uma construção diuturna, constante e perseverante. As palavras do nosso poeta maior, Carlos Drummond de Andrade, são as que melhor resumem este momento.

Estou preso à vida e olho meus companheiros. Estão taciturnos, mas nutrem grandes esperanças. Entre eles, considero a enorme realidade. O presente é tão grande, não nos afastemos. Não nos afastemos muito, vamos de mãos dadas. (Mãos Dadas, Carlos Drummond de Andrade)

Estocolmo, julho de 2012 